\title{
REMOÇÃO DE FRAGMENTO DENTÁRIO DESLOCADO EM CAVIDADE ORAL POR PROJÉTIL DE ARMA DE FOGO \\ - relato de dois casos
}

\begin{abstract}
João Nunes Nogueira Neto*, Ana Luzia Oliveira Boccanera**, Thiago Felippe Oliveira de Macêdo***, Marcelo Victor Omena Caldas Costa***, Joaquim Almeida Dultra****

Autor correspondente: João Nunes Nogueira Neto - joaonnneto@gmail.com

* Residente do Serviço de Cirurgia e Traumatologia Bucomaxilofacial da Universidade Federal da Bahia, Hospital Geral do Estado e Hospital Santo Antônio, Salvador, Bahia, Brasil

** Interna do Serviço de Cirurgia e Traumatologia Bucomaxilofacial da Universidade Federal da Bahia e Hospital Geral do Estado, Salvador, Bahia, Brasil

*** Cirurgião Bucomaxilofacial pelo Serviço de Cirurgia e Traumatologia Bucomaxilofacial da Universidade Federal da Bahia, Hospital Geral do Estado e Hospital Santo Antônio, Salvador, Bahia, Brasil

**** Preceptor do Serviço de Cirurgia e Traumatologia Bucomaxilofacial da Universidade Federal da Bahia e Hospital Santo Antônio, Salvador, Bahia, Brasil
\end{abstract}

\section{Resumo}

Ferimentos por Projétil de Arma de Fogo (FPAF) são considerados, dentro do segmento trauma facial, o segundo colocado em causas de morte, sendo superado apenas pelos acidentes automobilísticos. Ferimentos que possuem essa característica, causam fraturas cominutivas e com grande perda de substância dificultando a reconstrução do local afetado. Além disso, fragmentos resultantes, sejam do projétil ou da superfície do tecido afetado, podem ser deslocados para outras regiões sendo um fator a mais de atenção durante a avaliação. Os exames de imagem, como a tomografia computadorizada, são fundamentais para determinar a presença de fraturas ou de corpos estranhos. Dessa forma, os fragmentos deveriam ser removidos cuidadosamente bem como dentes e tecidos inviáveis, seguido de debridamento conservador e fechamento da ferida. O presente trabalho temo como objetivo, relatar dois casos de pacientes acometidos por projétil de arma de fogo, cujos fragmentos dentários foram deslocados para outros espaços da cavidade oral, com sua remoção realizada em âmbito ambulatorial tardiamente, abordando seus aspectos técnicos.

Palavras-chave: Violência; Ferimentos e Lesões; Traumatismos Maxilofaciais. 


\title{
REMOVAL OF TOOTH FRAGMENT DISPLACED BY FIREARM PROJECTILE IN ORAL CAVITY \\ - case report •
}

\begin{abstract}
Within the facial trauma field of study, injuries from firearm projectiles are considered the second most common death cause, surpassed only by car accidents. Such injuries can result in comminuted fractures causing great substance loss and making it rather difficult to reconstruct the affected site. Furthermore, tissue fragments, the projectile itself or affected surface can be displaced to other regions in the oral cavity. The imaging exams, like computed tomography, are essential for determining fractures or foreign bodies. Any fragments as well as unviable tissues and teeth should be carefully removed, by conservative debridement and wound repairs. This study aims to report two cases of patients wounded by firearm projectiles in which teeth fragments were displaced to other areas of the oral cavity. They were removed later on in an outpatient clinic.
\end{abstract}

Keywords: Violence; Wounds and Injuries; Maxillofacial Injuries.

\section{INTRODUÇÃO}

Os Ferimentos por Projétil de Arma de Fogo (FPAF) constituem um problema de saúde pública mundial, sendo a região maxilofacial alvo constante desse tipo de injúria. Esses ferimentos produzem lesões perfuro-contusas cujo perfil varia, de acordo com o calibre da arma usada, em distância e tecido acometido.(1) Durante o trauma, é comum o deslocamento das estruturas afetadas para outras regiões do complexo maxilofacial. Fragmentos ósseos e dos dentes, bem como do projétil envolvido, podem acarretar danos às estruturas adjacentes $\mathrm{e}$ permanecerem alojadas nesses outros espaços. Assim, é importante avaliar a trajetória do projétil e correlacionar com as estruturas afetadas. ${ }^{(2,3)}$

Para uma avaliação mais precisa é necessária a utilização de exames de imagem. Radiografias e tomografias computadorizadas permitem uma avaliação dessas estruturas deslocadas e seu exato posicionamento. (3) Dentre os exames utilizados, a tomografia computadorizada é considerada o pa- drão ouro para a avaliação de traumas no complexo maxilofacial. Ela permite avaliar com precisão fraturas e presença, da maioria, de corpos estranhos, principalmente quando estão profundamente alojados. ${ }^{(3)}$

As remoções de fragmentos ósseos, dentes fraturados, projéteis de arma de fogo ou outros corpos estranhos podem ser potencialmente fatais $e$ sua indicação deve ser criteriosa, principalmente quando existe suspeita de lesões vasculares associadas. Para o tratamento é necessário uma abordagem multidisciplinar precisa, com a localização e tamanho dos defeitos relacionados ao grau de dificuldade. . $^{(2,3)}$

Assim, o objetivo desse trabalho é relatar dois casos de pacientes acometidos por projétil de arma de fogo, cujos fragmentos dentários foram deslocados para regiões distintas da cavidade oral e removidos posteriormente sob anestesia local. 


\section{RELATO DE CASO 1}

Paciente R.C.N.R., 37 anos, gênero feminino, compareceu ao ambulatório de Cirurgia e Traumatologia Bucomaxilofacial da Universidade Federal da Bahia (UFBA) com histórico de FPAF em face há 2 anos e queixa de dor à abertura bucal. Ao exame clínico, pode-se observar ausência de mobilidade atípica maxilo-mandibular, ferimentos já cicatrizados, abertura bucal com sintomatologia dolorosa e ausência do elemento dentário 3.8. Na radiografia panorâmica foi observado um corpo estranho radiopaco em região posterior de mandíbula esquerda e foi solicitado o exame de tomografia computadorizada onde confirmou a ausência de fraturas do complexo maxilofacial e presença de imagem compatível com fragmento dentário deslocado para região ptérigomandibular esquerda (figura 1). Optou-se pela remoção do fragmento em âmbito ambulatorial, sob anestesia local com Lidocaína $2 \%$ com epinefrina 1:100.000 e realização de incisão tipo envelope por vestibular com descolamento até região lingual. O fragmento dentário se encontrava visível, foi facilmente removido com auxílio de pinça Allis para preensão e pinça Mixter para divulsão do tecido e realizou-se sutura com fio de nylon 5-o (figura 2).

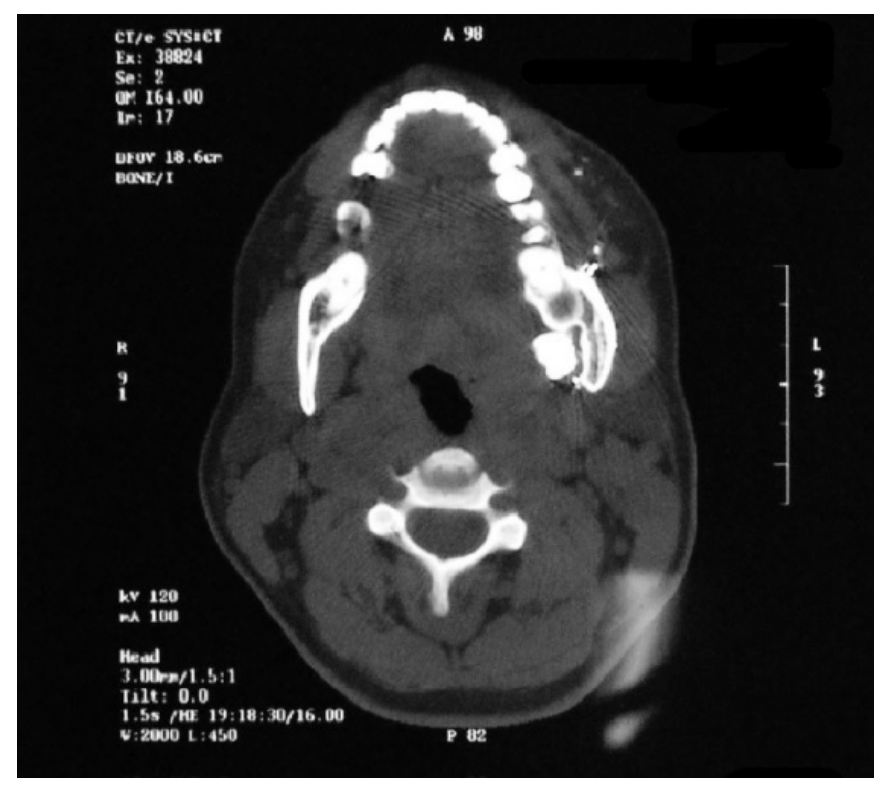

Figura 1 - Exame tomográfico com imagem compatível de dente em região ptérigomandibular esquerda

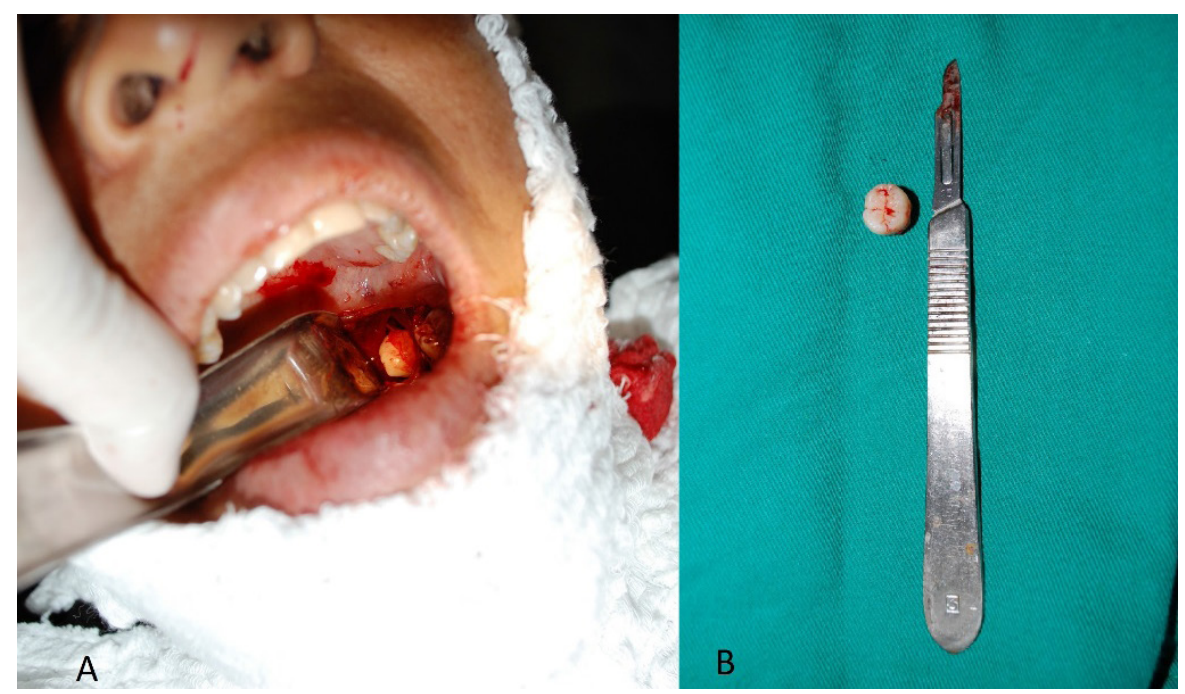

Figura 2 - A: Avaliação no transoperatório do fragmento. B: Fragmento removido 
O pós-operatório ocorreu sem intercorrências e com preservação das funções nervosas. O paciente foi submetido apenas ao uso de antinflamatório não esteroidal e analgésico, cursando sem sintomatologia dolorosa pós-operatória com acompanhamento de um mês com melhora da abertura bucal.

\section{RELATO DE CASO 2}

Paciente A.B.S., 29 anos, gênero masculino, acometido por FPAF, foi atendido no Hospital Geral do Estado em Salvador, Bahia, Brasil. O paciente recebeu todo suporte inicial primário, com realização de suturas em região bucal direita e dorso lingual.
Foi solicitado exame de imagem por tomografia computadorizada e observou-se elemento dentário deslocado para língua (figura 3). Em virtude da limitação de abertura de boca, dor e edema não foi possível realizar a remoção do mesmo na emergência. $O$ paciente ficou internado por 36 horas, e recebeu alta para acompanhamento a nível ambulatorial. Porém o mesmo só retornou 4 meses após o tratamento com queixa de secreção purulenta na língua. Ao exame clínico, pôde-se observar a presença de fístula em margem lateral direita de língua com consistência firme à palpação local e drenagem de secreção purulenta, ausência de mobilidade atípica maxilo-mandibular, boa abertura bucal e ferimentos já cicatrizados (figura 4).

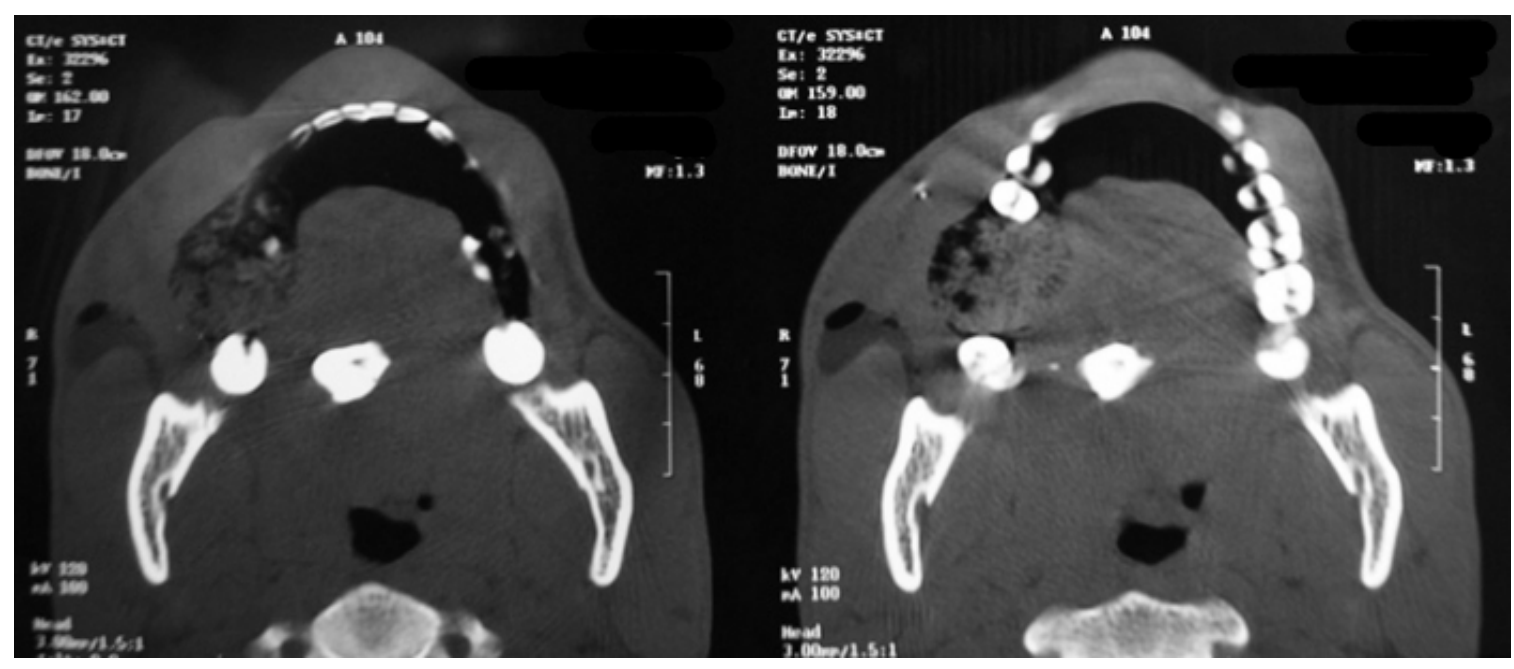

Figura 3 - Exame de tomografia computadorizada com imagem compatível com fragmento dentário em língua

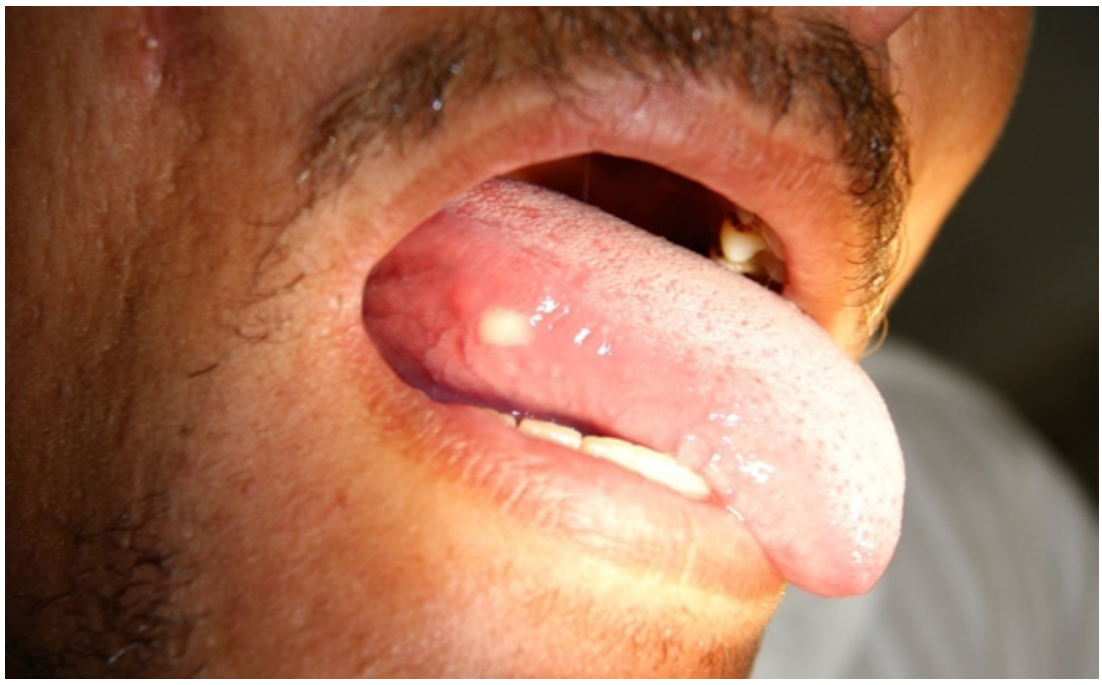

Figura 4 - Fístula em região lateral direita de língua 
Optou-se por realizar o procedimento em âmbito ambulatorial, sob anestesia local com Lidocaína $2 \%$ com epinefrina 1:100.000 na língua, seguida de uma incisão horizontal em margem lateral da língua com drenagem da secreção purulenta e posterior remoção do fragmento dentário que se encontrava dividido, sem maiores complicações (figura 5). Foi colocado sob a ferida cirúrgica um dreno de Penrose por 2 dias suturado com fio de nylon 4-0.

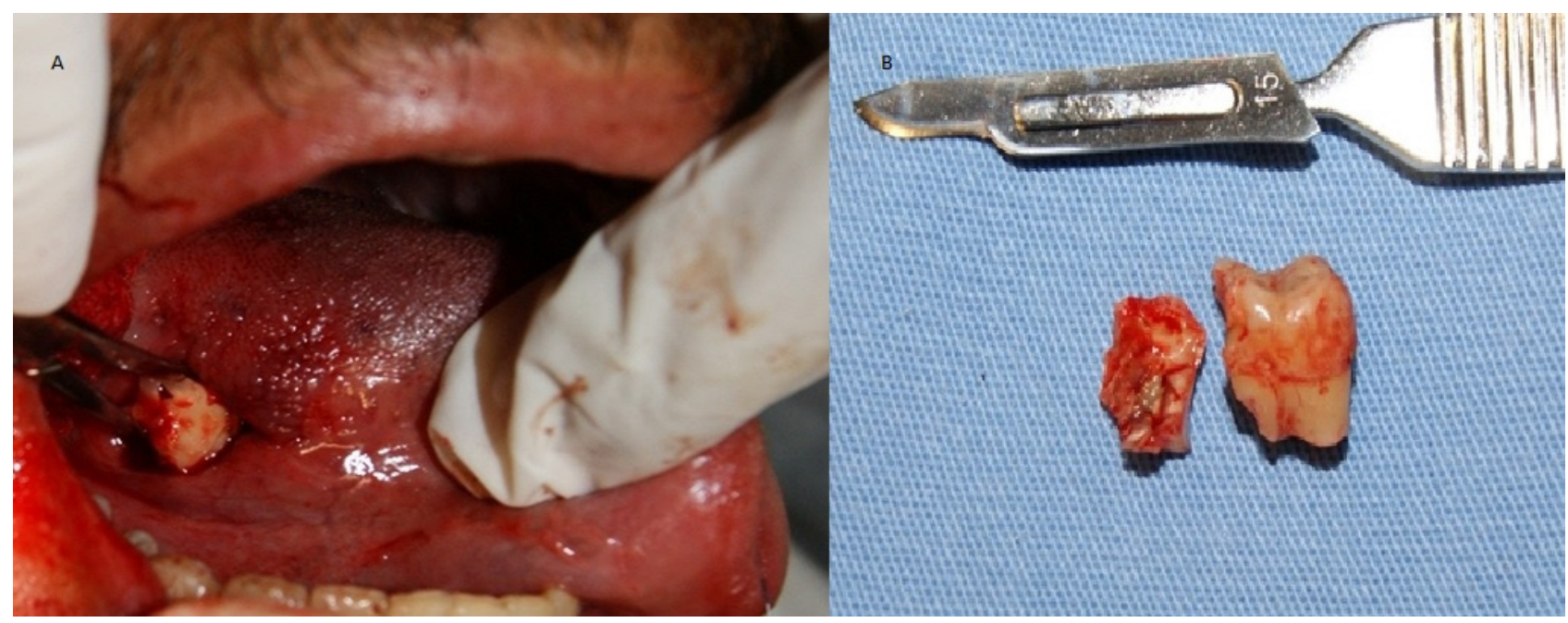

Figura 5 - A: Avaliação no transoperatório do fragmento dentário. B: Fragmento após sua remoção em dois pedaços

Foi prescrito Amoxicilina, 50omg, via oral, de 8 em 8 horas por 5 dias. O pós-operatório evoluiu sem intercorrências, sem sinais de afecção do nervo lingual e com ausência de infecção com um mês de acompanhamento.

\section{DISCUSSÃO}

A violência no Brasil é considerada um grave problema de saúde pública, afetando diretamente os gastos públicos, longevidade e qualidade de vida. Os FPAFs são considerados, dentro do segmento trauma, o segundo colocado em mortes, superado apenas por acidentes automobilísticos. ${ }^{(1,3)} \mathrm{A}$ maioria dos traumas em região maxilofacial ocorrem por agressão física e envolvem pacientes jovens do gênero masculino. (3)

O acometimento da região maxilofacial é comum por FPAFs. Estão relacionados a ele ferimentos com extensa destruição como fraturas cominutivas, lesões vasculares e avulsão de tecidos. ${ }^{(2)}$ Vários fatores como tipo de arma e calibre relacio- nado, distância, tipo de munição e o tecido atingido, influenciam diretamente este tipo de ferimento, tornando o atendimento inicial multidisciplinar e difícil.(1)

Um dos grandes riscos nesses pacientes é o comprometimento das vias aéreas provocado ou por trauma direto ou por edema subsequente, $(4,5)$ sendo necessário em casos mais graves, a intubação ou cricotomia. ${ }^{(1,2,6)}$ Outro fator de pode estar associado é a presença de lesões vasculares, a depender da localização anatômica afetada. Em suspeita de acometimento de estruturas vasculares ou grande proximidade delas, pode ser necessária a realização do exame de angiografia para afastar essa hipótese. ${ }^{(1,3)}$ Durante o procedimento nesses casos deve ser necessária a presença do cirurgião vascular.

Em situações que o corpo estranho esteja alojado em assoalho bucal, as imagens podem mimetizar sialolitos de glândulas submandibulares, dessa forma é importante correlacionar as imagens com o histórico clínico do paciente. ${ }^{(4)}$ Nos casos analisados o diagnóstico foi realizado sem dificuldade, 
pois os fragmentos estavam deslocados para a língua, região pouco comum, ${ }^{(4)}$ e região ptérigomandibular, fato não encontrado pelo autor na literatura. Em ambos os casos, não houve correlação com estruturas nobres sem necessidade de outros especialistas.

As complicações que podem surgir a partir de fragmentos deslocados de dentes incluem infecção, danos abainhas de vasos, nervos e até broncoaspiração. ${ }^{(5,7)} A$ remoção do projétil ou do dente é realizada se estiverem superficialmente ou provocando limitação funcional, próximo a estruturas nobres ou locais anatômicos de difícil acesso. O mesmo pode ser sepultado, se monitorado por meio de exames de imagens como a tomografia computadorizada, já que o tratamento não deverá ser mais danoso que a causa

Tomografias computadorizadas são melhores para identificação do corpo estanho e sua correta localização. ${ }^{(1,8)}$ Apesar de produzir artefatos durante avaliações de estruturas metálicas, ${ }^{(3,8)}$ como a relacionada ao trauma, ela foi fundamental no caso visto que o projétil foi previamente removido no atendimento inicial, restando apenas a estrutura dentária. No primeiro caso a paciente possuía exame radiográfico panorâmico, porém, não foi possível determinar exatamente sua correta localização, sendo possível apenas por análise tomográfica.

Autores $^{(2,3,7)}$ apontam como desnecessário o uso de antibióticos no pós operatório de remoções de corpos estranhos que não possuem sinais de infecção prévio, assim como foi feito no caso 1, que evoluiu com boa evolução após a remoção. No caso 2 foi prescrito amoxicilina devido à presença de sinais de infecção no pré-operatório, $(2,3,6,7,9)$ que regrediu com a remoção do dente alojado.

\section{CONSIDERAÇÕES FINAIS}

Devido à sua peculiar característica, os ferimentos provocados por arma de fogo não possuem um padrão de tratamento. É importante a experiência clínica da equipe responsável para adotar o melhor tratamento para cada paciente. Nos dois casos relatados os fragmentos dentários foram deslocados para regiões pouco comuns na literatura. Em ambos os casos, o tratamento de escolha foi a remoção do corpo estranho sob anestesia local em âmbito ambulatorial sem demais intercorrências.

\section{REFERÊNCIAS}

1. Pereira CCS, Jacob RJ, Shinohara EH. Fratura mandibular por projétil de arma de fogo. Rev Cir Traumatol Buco-Maxilo-Fac. 2006;6(3):39-46.

2. Sammartino G, Marenzi G, Mortellaro C. Transoral extraction of an intramuscularly retained bullet. J Craniofac Surg. 2010:21(1):124-5.

3. Nogueira Neto JN, Muniz VRVM, Figueiredo LMG Freire FPF, Souza AS. Ferimento provocado por arma branca impactada em região maxilofacial: Relato de caso. Rev Cir Traumatol Buco-MaxiloFac. 2015;15(1):45-48.

4. Santos T, Melo AR, Pinheiro RTA, Antunes AA, De Carvalho RWF, Dourado E. Tooth embedded in tongue following firearm trauma: report of two cases. Dent Traumatol. 2011;27(4):309-13.

5. Da Silva JJ, Machado RA, Nascimento MM, Brainer D, Macedo T, Valente R. Lesão por arma de fogo em terço inferior de face de criança: relato de caso. Rev Cir Traumatol Buco-MaxiloFac. 2004;4(3):163-8.

6. Diaz JCQ, Gozalez RP, Lazo SL, Rivera AG. Herida máxilo facial por arma de fuego en una mujer: presentación de un caso. Acta Odontol Venez. 2010:48(2):1-5.

7. Munerato MC, Da Cunha FS, Tolotti A, Paiva RL. Tooth fragments lodged in the lower lip after traumatic dental injury: a case report. Dent Traumatol. 2008;24:487-89.

8. Kelly P, Drago CJ. Surgical and prosthodontic treatment of a patient with significant trauma to the middle and lower face secondary to a gunshot wound: a clinical report. J Prosthodont. 2009;18(7):626-637.

9. Siqueira P, Carvalho PH, Duarte BG, Novaes Júnior VM, Bissonho CVF, Roter M. Fratura mandibular por projétil de arma de fogo: Relato de caso clínico. Rev Odontol UNESP. 2O12; $41(2): 133-38$ 